\title{
They See a Rat, We Seek a Cure for Diseases: The Current Status of Animal Experimentation in Medical Practice
}

\author{
Elijah O. Kehinde \\ Division of Urology, Department of Surgery, Faculty of Medicine, Kuwait University, Kuwait City, Kuwait
}

\section{Key Words}

Animal models - Basic research - Pharmaceutical research .

Toxicity testing $\cdot$ Experimental surgery $\cdot$ Ethics $\cdot$ Animal welfare

\begin{abstract}
The objective of this review article was to examine current and prospective developments in the scientific use of laboratory animals, and to find out whether or not there are still valid scientific benefits of and justification for animal experimentation. The PubMed and Web of Science databases were searched using the following key words: animal models, basic research, pharmaceutical research, toxicity testing, experimental surgery, surgical simulation, ethics, animal welfare, benign, malignant diseases. Important relevant reviews, original articles and references from 1970 to 2012 were reviewed for data on the use of experimental animals in the study of diseases. The use of laboratory animals in scientific research continues to generate intense public debate. Their use can be justified today in the following areas of research: basic scientific research, use of animals as models for human diseases, pharmaceutical research and development, toxicity testing and teaching of new surgical techniques. This is because there are inherent limitations in the
\end{abstract}

use of alternatives such as in vitro studies, human clinical trials or computer simulation. However, there are problems of transferability of results obtained from animal research to humans. Efforts are on-going to find suitable alternatives to animal experimentation like cell and tissue culture and computer simulation. For the foreseeable future, it would appear that to enable scientists to have a more precise understanding of human disease, including its diagnosis, prognosis and therapeutic intervention, there will still be enough grounds to advocate animal experimentation. However, efforts must continue to minimize or eliminate the need for animal testing in scientific research as soon as possible.

(c) 2013 S. Karger AG, Basel

\section{Introduction}

The use of animals in scientific research has always generated intense public debate and remains unacceptable in principle to some laymen as well as some scientists even today for many reasons [1-3]. These reasons range from the concern for the welfare of laboratory animals used for experimentation, failure of animal models to adequately represent human disease and, to some laymen and scientists, questioning the very notion that initial an-

\begin{tabular}{ll}
\hline KARGER & $\begin{array}{l}\text { ( ) 2013 S. Karger AG, Basel } \\
1011-7571 / 13 / 0227-0052 \$ 38.00 / 0 \quad \text { Karger }\end{array}$ \\
$\begin{array}{l}\text { E-Mail karger@karger.com } \\
\text { www.karger.com/mpp }\end{array}$ & $\begin{array}{l}\text { This is an Open Access article licensed under the terms of the } \\
\text { Creative Commons Attribution-NonCommercial 3.0 Un- } \\
\text { ported license (CC BY-NC) (www.karger.com/OA-license), } \\
\text { applicable to the online version of the article only. Distribu- } \\
\text { tion permitted for non-commercial purposes only. }\end{array}$
\end{tabular}

Prof. Elijah O. Kehinde, MD, MBBS, FRCS

Department of Surgery, Division of Urology

Faculty of Medicine, Health Sciences Centre

Kuwait University, PO Box 24923, Safat 13110 (Kuwait)

E-Mail ekehinde@ hsc.edu.kw or ekehinde@ hotmail.com 
imal experimentation of new drugs is of any benefit to mankind [1-3]. However, most objective scientists and many members of the public agree that animal research should be permitted as long as it is carried out for good reason, using humane conditions as much as possible, where there are no feasible alternatives and under strict regulation $[1,4-6]$. This is because most scientists agree that experiments involving the use of animals have great potentials like facilitating innovation, developing platform technologies and very often providing a link with clinical trials. In addition, animal experimentation is useful in exploring disease mechanisms, in validating and testing new targets for drug research and in providing insights into drug toxicity and interactions [5-13]. The objectives of this review are the following: (1) to provide a scientific basis for animal experimentation; (2) to discuss controversies surrounding animal experimentation; (3) to describe briefly animal models available for studying benign and malignant disorders, and (4) to discuss briefly diseases suited to animal experimentation.

\section{Evidence Acquisition}

The PubMed and Web of Science databases were searched using the following key words; animal models, basic research, pharmaceutical research, toxicity testing, experimental surgery, ethics, animal welfare, benign, malignant diseases. Important relevant reviews, original articles and references from 1970 to 2012 were reviewed for data on the use of experimental animals in the study of diseases, with focus on urological diseases. About 161 articles were abstracted for type of experiments, type of animal models used, number of experimental animals used, analysis and conclusions. Relevant chapters of 11 textbooks were reviewed. In addition, the websites of $19 \mathrm{com}$ panies and societies with information germane to the topic were reviewed. An assessment was made of the benefits of the experimental animal models used and whether in vitro study and computer simulation in some cases could have provided an equally satisfactory model.

\section{Evidence Synthesis}

Historically, animals have been used for a wide range of scientific research that has proved beneficial to mankind, particularly in relation to the advancement of scientific knowledge, drug development for use in animals and humans, training in surgical techniques, the safety of

Current Status of Animal

Experimentation chemical products and, very importantly, the safe development of vaccines $[1,5,6]$. Animal experimentation was frowned upon by laymen and scientists primarily because of the pain and suffering to which some scientists subjected experimental animals between the 19th and mid-20th centuries $[1,5,7-10]$. This led to the formation of groups of people concerned about the welfare of nonhuman animals used in experimental work in many countries of the world and forced the scientific community to come up with regulations that ensured that animals subjected to experimentation did not suffer undue distress or pain [13-15]. Similarly, the vehemence of attacks by animal rights activists in some countries in the 1980s has led to the cessation of the use of animals for the testing of cosmetic products, alcohol and tobacco [16]. Animal rights activists as used in this article refers to a group of people who hold extremist views about research involving animals to the extent that they are ready to use violent means to stop all research involving the use of laboratory animals (vide infra). This group should be distinguished from people concerned about the welfare of non-human animals used in experimental work or people with concerns for animal welfare in general $[1,14$, 16]. The rise in the influence of animal rights activist groups has also forced the scientific community to use animals that can be easily concealed in the laboratory (mice, rabbits, etc.) as opposed to the use of monkeys or the great apes which are difficult to conceal [13-15]. The other reasons for the widespread use of small laboratory animals, particularly mice, are that they are cheap, widely available and easy to take care of and have a shorter generation time - the generation time being the combination of gestation period, time to sexual maturity and overall life span.

At the present time, most non-scientists (including many people with concerns for animal welfare) and scientists agree that a world in which the important benefits of scientific research can be tapped but without causing undue pain, distress, suffering or death to the animals being used for research should be the ultimate goal $[1,12$, 14-16]. The use of laboratory animals can still be justified today in the following areas of research: basic scientific research, use of animals as models for human diseases, pharmaceutical research and development, toxicity testing and surgical skills training or simulation $[6,12,16]$. This is because there are inherent limitations in the use of alternatives like in vitro study, human clinical trials or computer simulation. It should be noted that there are problems of transferability of results obtained from animal research to humans. Efforts are on-going to find suit- 
able alternatives to animal experimentation. Among the methods being explored are cell and tissue culture, computer simulation and postmortem research $[2,3,6,17$, $18]$.

\section{Types of Research Involving Animals}

There are five main reasons for the continued use of animals in research. These include basic scientific research, their use as models for human diseases, pharmaceutical research, toxicity testing and surgical skills training or simulation.

\section{Animals Used for Basic Scientific Research}

The aim of basic research is to increase scientific knowledge about the way animals and humans behave, develop or function biologically. This type of research may not necessarily lead to applications for humans, although a primary objective is that it may eventually lead to applications from which humans may directly benefit. It covers areas such as observational research, assessment of physiological mechanisms and developmental and genetic studies. Of these, the most important is perhaps physiological research [16]. These studies involve surgical, dietary or drug treatments that are directed at a better understanding of function at the physiological, cellular or molecular levels and have made significant contributions to current knowledge about human and animal biology and medicine. In fact, it has been said that much of current modern medicine is evidence-based basic research. For example, most of our current knowledge about the endocrine, immune and nervous systems has emerged from research involving animals. Research involving the use of immune-deficient rodents has contributed very substantially to our understanding of the complex processes of diseases that affect the immune system, neoplasia, HIV/AIDS and other diseases $[6,11,12,16,18]$.

\section{Animals as Models for Human Diseases}

Laboratory animals are also often used as models for understanding of disease processes and to develop new vaccines and medicines [16, 19, 20]. Very often these types of research draw on findings derived from basic scientific research. For example, animal models using the chimpanzee and monkey were employed extensively for the study of hepatitis B and poliomyelitis leading to the development of effective vaccines against these diseases [21-24]. Similarly, much of the current knowledge about hepatitis $\mathrm{C}$ has been derived from studies in the chimpan- zee as for a long time it was the only non-human host for the virus. Unfortunately, unlike hepatitis B, an effective vaccine against hepatitis $C$ is yet to be discovered. Animal models may be difficult to find or develop for some diseases such as HIV/AIDS and some cancers [24-26]. This is due to the complex pathogenesis of these diseases and their many different subtypes in humans and animals, which makes it inherently difficult to study them and to develop successful animal models [3, 24-26]. Another important area of animals as models for human diseases involves the use of genetically modified animals. Effective treatment has been developed for some types of cancer, such as breast cancer (tamoxifen) and prostate cancer (goserelin), based in part on the study of transgenic mice that express human receptors on their cells, which were used as replacements for primates. These animals are genetically modified to study the role of genes in disease processes $[16,19,20]$ because the pathology of various diseases (neoplastic, infectious, nutritional, inherited, etc.) is affected directly or indirectly by an individual's genome. The study of genetics, therefore, can help in the understanding of these fundamental interactions.

The sequencing of the human and mouse genomes has revealed remarkable similarities. About $99 \%$ of the genes in these two genomes have direct counterparts in the two species. Therefore, the mouse is used extensively as a model for research on human diseases in various types of studies. Furthermore, because mice breed rapidly and are easy to look after in the laboratory, and because the methods of genetic modification are more effective in mice compared with other mammals, they are a favoured species in genetic modification studies. Other animals used in genetic modification studies include rats and zebrafish.

At present, it can be argued that the use of genetically modified animals as models has allowed researchers to generate more accurate and appropriate models of human diseases that have facilitated progress and has made it more likely that research findings in such models will transfer to human subjects more quickly. While most animal models cannot be considered exact replicas of human diseases, most biomedical scientists working in the field are of the view that there are often enough similarities between mice and humans to make informative comparisons [16]. Examples include findings from models used for diabetes, deafness, psychiatric disorders, neurodegenerative disorders and some cancers. However, it should be noted that when scientists think that they have a good model, it is often difficult to determine how much its attributes are due to its genes or to environmental factors. This is because, in some instances, wildly differing
Kehinde 
results have been found to occur in different laboratories using the same strains of animal in the same procedures. This observation is itself becoming an important area of further research. The use of genetically modified animals has a wide range of welfare implications because the animals involved usually suffer from the disease being studied for the duration of their lives [16]. These animals are also likely to be the subject of procedures carried out to characterize the different stages of the disease, including blood, metabolic and behavioural tests. These procedures may inflict pain or cause distress to the animals. On this note, it can be argued that people concerned about the welfare of non-human animals have a valid point.

\section{Pharmaceutical Research}

In the past 80 years, pharmaceutical research and development has been transformed because of the availability of advanced information and diagnostic technologies, better understanding of genetics and increasing use of computational analysis [27]. Consequently, a wide range of advanced methods that do not involve animals is used in conjunction with animal research for pharmaceutical research and development. Overall, there has been a substantial reduction in the total number of animals used for pharmaceutical research [16]. However, it still remains responsible for a significant proportion of the animal experiments conducted in most countries in Europe and the USA at the present time [11,28-30]. As part of the search for new medicines and vaccines for use in humans, a very wide range of basic and applied medical and veterinary research projects is supported or conducted by pharmaceutical companies. It has been estimated that $60-80 \%$ of animal experimentation used for pharmaceutical research and development are in the characterization of promising candidate drugs and about $5-15 \%$ are used in the discovery and selection process $[11,31,32]$. In the early stages of development of new medicines to assess the importance of a drug target, genetically modified mice are most commonly used. They are also used increasingly in target validation of new medicines or as animal models of diseases. For certain biological compounds such as vaccines, animal testing is mandatory for each batch that is produced, to ensure potency and safety $[22,28,31,33]$. It is possible that the use of animals for pharmaceutical research and development will continue to decline as the use of advanced methods or other alternatives increases. On the other hand, the use of animals may remain unchanged because advanced imaging, sensing and the use of biomarkers will allow the extraction of more information $[27,34,35]$. It is difficult to envisage a

Current Status of Animal

Experimentation future in which there will be a rise in the use of animals for pharmaceutical research and development. The current ethical debate on the use of animals for experimentation as well as increasing violent activities of animal rights activist groups will most likely ensure that this does not happen $[2,9,10,13,16,36,37]$. While the violent activities of some animal rights activists should be condemned, scientists too need to do a better job of explaining to the public the justification for animal research today $[14,16]$.

\section{Toxicity Testing}

Toxicological studies are often carried out on animals to help test the safety of a wide range of substances that could be harmful to humans, animals and the environment $[16,38,39]$. These tests are carried out on new products like medicines, household and industrial chemicals, agrochemicals and food additives. Some of these chemicals are tested for their potential to cause irritation, produce physiological reactions, induce cancers, produce a teratogenic effect on the developing fetuses in utero and produce adverse effects on fertility [40]. Specified doses and exposures of the chemicals are given to animals, from which information regarding safe human dose and exposure levels is then determined. In order to observe the effects seen when a new product is used, misused or abused in different situations, the tests usually range from one single high dose to long-term exposure to a particular chemical. Furthermore, the tests are designed to mimic the possible routes of exposure that humans might be subjected to, such as through the mouth, skin, eyes or airways.

Various species of animals are used for toxicological testing or safety evaluation of medicines. These include rats and mice (most commonly), larger animals like rabbits and dogs, and less often primates like chimpanzees and monkeys, as well as fish and chickens in some instances. It has been observed that a full complement of toxicity tests for a pharmaceutical compound that reaches the market usually involves preliminary testing on $1,500-3,000$ animals. Occasionally, these toxicological tests are also used to assess the metabolism and efficacy of these products as well as drug interactions. It has been argued that computer modelling or simulation cannot provide adequate insight into new drug toxicity the way animal models can [38].

The relevance of initial toxicology studies in animals to actual experience in man has been the subject of intense debate $[2,3,13,17,39,41]$. This is because the concordance between short-term toxic effects of new pharmaceuticals in animals and humans (during clinical trials) has been reported to be about $71 \%[36,38]$. This 
means that $71 \%$ of acute toxicities in humans resulting from compounds that entered clinical trials were predicted by preclinical safety or toxicity studies in animals $[2,3$, $38,39,41]$. Drugs producing significant adverse effects in animals will obviously not progress to clinical trials $[1,6$, 16]. It has also been argued that for longer-term toxicities such as carcinogenicity and teratogenicity it has been difficult to establish the benefits if any of initial toxicology testing in laboratory animals $[40,41]$. This is because the concordance between animals and humans, in terms of long-term toxicity, has been found to be lower than the $71 \%$ obtained for short-term toxicities [39]. However, this may be due to the fact that assessment of long-term toxicity is a highly complex process.

\section{Surgical Skills Training or Simulation}

For many decades, live anaesthetized animals have been used as a method of educating, developing and refining complex surgical procedures $[42,43]$. A lot of developments that have taken place in reconstructive surgery, particularly in urological surgery, have taken place largely from the result of initial experimentation using laboratory animals. In recent times, it has been found that the use of laboratory animals is indispensable in the learning or teaching of new surgical skills like laparoscopic or robotic procedures [44-46]. These new techniques have a steep learning curve. Trainers have found that the use of inanimate and animate models have shortened the learning curves. Trainees can be assessed without putting any human lives in danger by training on live laboratory animals in a regulated environment before they are exposed to operating on humans under the supervision of a mentor. Many surgical training programs make use of inanimate simulators (for example bench and pelvic trainers) prior to the use of animal models [47-49]. Because animals like pigs, dogs, sheep and calves have similar anatomies and physiological responses to humans, they are often used in various laparoscopic and robotic training procedures. The physiological response to various surgical manipulations in these animals resemble those seen in humans, such as organ movements due to respiration, tissue resistance and reflection, vessel pulsations, and bleeding when vessels are cut. This makes them excellent models for training, unlike inanimate models where such complexity may be difficult to reproduce [48, 49]. From a practical point of view, despite some anatomical differences from the urinary tracts of humans, the porcine model is most often used for various urological procedures involving the kidneys, ureters, bladder, bowel and prostate [45].

\section{Limitations of Animal Models/Dangers of Extrapolation from Animals to Humans}

There are sometimes problems in developing effective experimental approaches in biomedical research and in extrapolating from animal models to humans. This is primarily because of the vast complexity and variability of biological systems $[2,17,50]$. The difficulties are an intrinsic part of any modelling approach that relies on surrogates for the range of organisms of interest. These difficulties are not confined to experimental animal studies, but are also encountered in developing and applying other experimental approaches such as in vitro and clinical studies [51, 52]. None of these two broad methods can reproduce exhaustively all the features that characterize the wide diversity and variation of genetic and biological processes that occur in humans.

\section{Limitations of Human Clinical Trials}

Even if the stage of animal research during the development of a new drug was omitted, intrinsic problems resulting from the way clinical trials are designed or conducted remain. This is because most initial clinical trials of a new drug in humans would typically require testing the new drug on about 3,000 human volunteers and patients. Consequently, if a side effect occurs in 1 in 10,000 patients, such side effects may not become apparent until after the product has been marketed $[52,53]$. Furthermore, human clinical trials often involve a relatively homogeneous sample of patients in order to distinguish clearly between the effects of the therapy against the background of variation between different patient responses $[51,52]$. Hence, most initial clinical trials frequently fail to provide any information about the effects of drug interactions, since they usually do not mimic the actual situation in real life where patients may be on several different medications at the same time $[2,17,53]$. Thus, uncertainties about the effects of treatments in the clinical setting are therefore inevitable and clinicians must not only be cautious in extrapolating the results of clinical trials to individual patients, but must remain vigilant for the occurrence of new side effects or drug interactions that failed to occur during initial clinical trials of a new drug $[52,53]$. A drug that clearly illustrates some of the abovementioned dangers is pioglitazone (Actos), which was introduced in 1999 for the treatment of diabetes mellitus [54]. It was not until it had been used for more than 8 years and by over one million patients that it was found to increase the incidence of bladder cancer. This increased incidence is seen mostly in men [54-57]. DOI: $10.1159 / 000355504$
Kehinde 


\section{Limitations of in vitro Research}

There is little doubt that there are major differences between human cells in vitro and in vivo which can pose challenges in extrapolating findings from research on the functioning of human cells in culture to the functioning of human cells in vivo $[2,17,50]$. While cell culture is cheap and easy, there is no doubt that the usefulness of data obtained from in vitro cultures is very limited. $\mathrm{Hu}$ man cells evolved to be part of an intact organism and what they do when dissociated is fundamentally different from what they do when they are a part of a large community of cells. It is therefore not surprising that more acute challenges arise in using the findings from cell culture studies to make predictions relating to the integrated physiology of intact tissues, organs or the whole human body compared to findings from intact animals.

From the above, it is clear that laboratory animals are useful in basic and applied forms of scientific research. In many cases, they can be useful models for studying aspects of human biology and disease and the likely effects of chemicals and medicines, particularly interactions between drugs. However, the usefulness of animal models has to be judged on a case by case basis for each type of research or testing. There is little doubt that initial experimentation in animals is preferable to the alternative of discovering major flaws in new drugs, vaccines or industrial or agrochemical products only after humans have been exposed to their harmful and in some cases debilitating side effects. This scenario most likely will increase the overall cost of new drug developments [54,55].

\section{Ethical Issues in Animal Experimentation}

There are currently about 4 different views regarding the ethics of animal experimentation. These are the 'anything goes' view, the 'on balance justification' view, the 'moral dilemma' view and the 'abolitionist' view [16]. It will not be hyperbolic to state that the correct ethical position on this contentious issue will be an amalgam of some elements of all 4 views [16]. This is because, in a field as controversial as animal experimentation, it is often a question of perception! Animal rights activists see a rat in a cage, while scientists are seeking a cure for diseases! There is no doubt that the welfare implications for animals used in research are as varied as the benefits. Most observational research on animals conducted in their natural habitats should have minimal negative effects. Similarly, there is a broad consensus by both those for and against animal research that animals used for

Current Status of Animal

Experimentation laboratory research should not experience unnecessary pain, suffering, deprivation of food and water, isolation or distress. Apart from ethical and legal considerations, pain and distress cause changes to the body that could interfere with the outcome of some research on animals. Consequently, minimizing pain and avoiding distress to experimental animals contributes to sound science. Animals that are used as disease models are likely to experience the symptoms typical for the disease. If part of the symptoms involves pain, it is important for the scientists involved in this type of research to look for ways of minimizing the pain. In the contentious world of animal research, the crucial question that needs to be answered by most protagonists of animal research remains how useful animal experiments are to prepare the way for trials of medical treatments in humans $[6,12,17,18]$. This is because generally public opinion is behind animal research only if it helps to develop better drugs or leads to increased understanding of a disease and therefore will lead to effective preventive methods or new drugs to combat such diseases. The abolitionist view is currently difficult to justify. While attempts continue to be made to find suitable replacements for the use of living creatures, it would appear that for many years to come research involving the use of live animals will continue to be required $[6,12]$. It has been rightly argued by Watts [6] that at present 'you could phase out the use of animals if you were prepared to put more risks on to humans'. It would also appear that our world is moving to the peril of such a view. The many cases of bladder cancer seen after the introduction of pioglitazone is a prime example. To summarize, all are agreed that there is a need to reduce rather than eliminate animal experimentation. At the same time, efforts must continue to find suitable replacements for animal experimentation as well as more refined techniques that avoid the use of intact live animals [37, 58-63].

\section{Legal Issues Affecting Animal Experimentation and Views of Animal Rights Activists}

Briefly, due largely to pressure groups opposed to animal experimentation, there is now legislation in place by International Regulatory Agencies, National Regulatory Agencies and Institutional Regulatory Boards whose role is to satisfy certain criteria before permission is granted to a researcher intending to conduct experiments involving laboratory animals [7-13]. These criteria include the following: 
- There is no other method of answering the question the experiments purport to address

- The animal's welfare is protected

- There is no undue stress to the animal

- There is adequate food and water

- Suitable light and comfort are provided for the animals

- Pain must be minimized by using anaesthetic agents, if necessary

In other words, the humane treatment of experimental animals must be ensured $[1,8,11,12,15]$. The current legal position is possibly best summed up in recommendations by a committee set up by the Academy of Medical Sciences, UK and chaired by Sir David Weatherall in 2006. The committee recommended that '... the use of non-human primates is impossible to abrogate at present (2007), there is a case for their use provided it is the only way of solving important scientific or medical questions and high standards of welfare are maintained'. (www. acmedsci.ac.uk/imagesproject/nhpdownl.pdf).

\section{Views of Animal Rights Activists}

The term 'animal rights activists' as used in this article has been previously defined (vide supra). The views of animal rights groups deserve special mention in this review and regarding the current legal position on research involving animals as enunciated above. It is well known that people have different views regarding the use of animals for companionship, food, clothing and research [1, $5,9,10,12,14]$. A widely held view is that people may use animals for these purposes if in return they provide them with shelter, adequate food and treatment. Animal rights activists believe it is wrong for people to remove animals from their natural habitats or interfere with their lifestyle. Some animal rights activists even oppose the eating of meat, meat products or eggs, drinking milk, wearing leather or fur, or keeping animals in zoos! Some also object to having animals as pets. They are also opposed to animal research as a matter of principle regardless of any potential benefits for humans and other animals $[7,9,13]$. Furthermore, some animal rights activists try to end practices they oppose vehemently by trying to influence public opinion and go as far as trying to get laws passed to stop all animal research. Worse still, some, particularly in Europe and the UK (Animal Liberation Front), have resorted to extreme measures like threatening researchers and members of their families, vandalizing laboratories, properties and cars and planting bombs to intimidate researchers into discontinuing their work $[1,14,16]$ ! It is heartening to note that even in Europe there is now legislation in place to protect scientists engaged in animal research against bitterly antagonistic attacks by groups with such extreme views $[12,14]$. To hold that people have an ethical responsibility towards animals in their care is to support animal welfare and most scientists engaged in animal experimentation subscribe to this notion as well $[1,12,14-16]$.

\section{Species of Animals Used as Experimental Models}

This topic will be discussed very briefly. There are many different species of animals that are currently used in research. Most of these are vertebrates and the majority of procedures involve the use of very small laboratory animals like mice and rats for reasons stated previously. Other mammals used on a very small scale include rabbits, pigs, dogs and primates (monkeys and chimpanzees) [27-30, 63-65]. Research involving the use of primates has almost ceased in most parts of the world and only few centres in the USA (e.g. National Institute of Health) holding licenses to use these large animals continue to use them as experimental animals [16]. Apart from being large, primates are expensive to maintain, are potentially dangerous animals and have a very long generation time. The broad spectrum of animals used as models include the following:

- Rodents: hamsters (Syrian, Chinese, Swedish), mice (nude, non-nude), rats (Sprague-Dawley, Wistar), guinea pigs, wild rats

- Lagomorphs: rabbits (wild, New Zealand white, Dutch)

- Carnivores: cats, dogs (beagles, mongrels)

- Ungulates: pigs, mini pigs, sheep, goats, cattle, horses

- Primates: monkeys (e.g. rhesus, macaques), chimpanzees

- Genetically modified animals: mostly rodents (mouse)

- Reptiles: snakes, lizards

- Amphibians: frogs, newts

- Birds: eggs, chickens

- Fish: zebrafish used in genetic modification studies

\section{The Use of Invertebrate Animals as Models}

Invertebrates like the fruit fly Drosophila, the nematode worm Caenorhabditis elegans and some species of snails (molluscs), yeasts, bacteria and viruses are also used in experimental research, albeit on a very limited scale. The genetic modification of these animals has been found to provide useful information regarding the fundamental biological role of genes [66]. However, studies in these invertebrates cannot address questions that concern the
Kehinde 
effects of gene modification on physiological disease processes or the development of organs that are only found in vertebrates or mammals $[16,66]$. Because of their close association with the environment and diversity of habitats, invertebrates are more at risk for adverse responses to environmental pollutants [67]. They are therefore often used in studies examining the effects of exposure to environmental contaminants. The use of these invertebrates in experimental research does not generate the same controversies as those involving the use of vertebrate animals.

\section{The Use of in silico Models}

In silico models involve the use of computer simulation to predict biological events. The use of in silico approaches has increased the ability to predict and model the most relevant pharmacokinetic, metabolic and toxicity endpoints, thereby accelerating the drug discovery process [68]. On the other hand, in silico polymerase chain reaction (PCR), also referred to as digital PCR, virtual PCR, electronic PCR or e-PCR, refers to computational tools used to calculate theoretical PCR results using a given set of probes to amplify DNA sequences from a sequenced genome $[69,70]$. Many software packages are available offering differing balances of feature set, ease of use, efficiency and cost. One of the most widely used is ePCR, which is freely accessible from the National Center for Biotechnology Information (NCBI) website. The use of these techniques in drug discovery, PCR and other applications is in its infancy. The disadvantages of using results from in silico models are about the same as those of using results from in vitro studies described previously. If results obtained from in silico models are borne out in clinical trials, then hopefully this technique may contribute directly to a reduction in the need for animal experimentation.

\section{Methods of Induction of Cancer}

These will be described very briefly. Studies involving different cancers are major reasons for embarking on animal research. Cancers in experimental animals can be induced using any of the following techniques [62-65]:

- Spontaneous induction of cancer: prostate cancer is seen in dogs older than 8 years; $80 \%$ of transgenic adenocarcinoma of mouse prostate (TRAMP) mice older than 16 weeks develop prostate cancer spontaneously; cattle fed on bracken fern in the Balkans and Turkey develop bladder cancer; 24 and 51\% of male and fe-

Current Status of Animal

Experimentation male Wistar rats, respectively, develop spontaneous bladder cancers, indicating the role of hormones in the induction of some cancers; the incidence of spontaneous bladder cancer is about $28 \%$ in the male brown Norway rat; ageing macaque monkeys often spontaneously develop colon and breast cancers [65].

- Hormonal induction: Noble rat given subcutaneous steroid and cholesterol combination will develop prostate cancer or the use of oestrogens, e.g. $75 \%$ of male Syrian golden hamsters given $20 \mathrm{mg}$ of diethylstilboestrol subcutaneously will develop prostate cancer

- Transplantable: Dunning R-3327 or Pollard rat prostate adenocarcinoma system

- Human xenografts: nude mice, SCID mice

- Chemicals: nitroso-N-methyl-N-dodecyclamine (NNN) and N-methyl-N-nitrosourea (NMU) given by intravesical route will produce bladder cancer in Wistar rats; nitrocompounds (2 acetyl aminofluorene (AAF) and N-butyl-N-(4hydroxybutyl)-nitrosamine (BBN), NNN and NMU given intravenously to rats or dogs will induce bladder cancers, while nitroso compounds such as intravenous dimethylnitrosamine (DMN) will produce bladder cancers in about $63 \%$ of Wistar rats

- Irradiation: about $7 \%$ of Wistar rats given $660 \mathrm{rad}$ will develop bladder cancers

- Genetic engineering: knockout 'PTEN' gene induces prostate cancer in old mice

- Others (viral infection): herpes virus induces cancer in frogs

Examples of diseases suitable for animal experimentation include benign diseases like ischaemic/reperfusion injury (e.g. torsion of testis, renal transplantation and myocardial ischaemia), benign prostatic hyperplasia, and malignant diseases like cancers of the liver, colon, prostate and bladder.

\section{Conclusions}

Animal research remains justifiable today for the following reasons: (1) it is less costly and takes a shorter time to conduct compared to clinical trials; (2) it involves less ethical constraint than human clinical trials; (3) it opens avenues for investigations of the genetic, aetiological, morphological and natural history aspects of some diseases like cancers, and (4) it provides a unique opportunity for the development of new concepts which are difficult to obtain through clinical trials or computer simulation. Animal models and clinical trials must work in concert to assist in the search for new and more effective 
treatment of diseases. Initial testing of new drugs on experimental animals reduces the risk of dangerous side effects in humans, although they cannot guarantee that such drugs will be safe for everyone who might use them subsequently. However, no efforts should be spared to find suitable and equally reliable replacements for animal research or reduce the need for animal research. For the future, it is likely that a combination of animal models, cell lines and computer simulations will, hopefully, allow researchers to develop a wide-ranging tool kit for modelling diseases.

\section{Acknowledgement}

This work was supported by Kuwait University research grant MS 02/99.

\section{Disclosure Statement}

None.

\section{References}

$\checkmark 1$ Goeke JE: The history of the use of animals in research and the development of the animal welfare concept. J Am Coll Toxicol 1987;6: 187-194.

2 Pound P, Ebrahim S, Sandercock P, et al: Where is the evidence that animal research benefits humans? BMJ 2004;328:514-517.

-3 Perel P, Roberts I, Sena E, et al: Comparison of treatment effects between animal experiments and clinical trials: systematic review. BMJ 2007;334:197-200.

4 Orlans FB: History and ethical regulation of animal experimentation: an international perspective; in Khuse H, Singer P (eds): A Comparison to Bioethics. Oxford, Blackwell Publication, 1998, pp 400-421.

5 Guerrini A: Experimenting with humans and animals: from Galen to animal rights. JAMA 2004;291:2133-2134.

6 Watts G: Animal testing: is it worth it? BMJ 2007;334:182-184.

7 Hopley E: Campaigning against Cruelty - The Hundred Year History of the British Union for the Abolition of Vivisection. London, BUAV, 1998.

8 Animal Welfare Organisations: Universities Federation for Animal Welfare (UFAW). http://www.ufaw.org.uk (accessed May 2012).

9 Fund for the Replacement of Animals in Medical Experiments (FRAME). http://www. frame.org.uk (accessed January 2012).

10 Royal Society for the Prevention of Cruelty to Animals (RSPCA). http://www.rspca.org.uk (accessed November 2011).

11 Association of the British Pharmaceutical Industry (ABPI) 2009. http://www.abpi.org.uk.

12 Coalition for Medical Progress (CMP). http:// www.medicalprogress.org (accessed November 2009).

13 British Union for the Abolition of Vivisection (BUAV). http://www.buav.org (accessed November 2012).

14 Matfield M: The Animal Liberation Front: terrorist attacks on animal research. Scand J Lab Anim Sci 1996;23:31-35.
5 Thomas D: Laboratory animals and the art of empathy. J Med Ethics 2005;31:197-202.

16 Nuffield Council on Bioethics: The Ethics of Research Involving Animals. London, Nuffield Council on Bioethics, 2005.

17 Blackmore C, Pearlfield T: Missing evidence that animal research benefits humans. BMJ 2004;328:1017-1018.

18 Giles J: Animal experiments under fire for poor design. Nature 2006;444:981.

19 Schuler AM, Wood PA: Mouse models for disorders of mitochondrial fatty acids $\beta$-oxidation. Inst Lab Anim Res 2002;43:5765.

20 Abbot A: Geneticists prepare for deluge of mutant mice. Nature 2004;432:541.

21 Choo OL, Kuo G, Weiner AJ, et al: Isolation of a cDNA clone derived from a blood borne non-A, non-B viral hepatitis genome. Science 1989;244:359-362.

22 Eggers HJ: Milestones in early poliomyelitis research (1840-1949). J Virol 1999;73:45334535.

23 Rutty CJ: The middle-class plague: epidemic polio and the Canadian state (1936-1937). Can Bull Med Hist 1996;13:277-314.

24 Lewis AD, Johnson PR: Developing animal models for AIDS research - progress and problems. Trends Biotechnol 1995;13:142150.

25 Cohen J: AIDS vaccine trial produces disappointment and confusion. Science 2003;299: 1290-1291.

26 Klausner RD, Fauci AS, Corey L, et al: Enhanced: the need for a global HIV vaccine enterprise. Science 2003;300:2036-2039.

27 Takahashi N, Smithies O: Human genetics, animal models and computer simulations for studying hypertension. Trends Genet 2004; 20:136-145.

28 Zon LI, Peterson RT: In vivo drug discovery in the zebra fish. Nat Rev Drug Discov 2005; 4:35-44.

29 Gibbs RA, Weinstock GM, Metzker ML, et al: Genome sequence of the Brown Norway rat yields insights into mammalian evolution. Nature 2004;428:493-521.
30 Herrera VL, Ruiz-Opazo N: Generic studies in rat models: insights into cardiovascular diseases. Curr Opin Lipidol 2005;16:179-191.

31 Corley TAB: The British Pharmaceutical Industry since 1851. Available at: http://www. rdg.ac.uk/Econ/Econ/workingpapers/ emdp404.pdf (accessed January 2009).

32 AstraZeneca: Take a Walk Along the Path to a New Medicine. 2003. Available at: http:// www.asterazeneca.com/sites/7/imagebank/ typeArticleparam502178/seeking_new_medicines_v15.html (accessed November 2011).

33 Berthet FX, Coche T, Vinals C: Applied genome research in the field of human vaccines. J Biotechnol 2001;85:213-226.

34 MacGregor JT: The future of regulatory toxicology: impact of the biotechnology revolution. Toxicol Sci 2003;75:236-248.

35 Griffin JF: A strategic approach to vaccine development: animal models, monitoring vaccine efficacy, formulation and delivery. Adv Drug Deliv Rev 2002;54:851-861.

36 Association of the British Pharmaceutical Industry: Clinical Trials - Developing New Medicines. 2003. Available at: http://www. abpi.org.uk/publications/briefings/clinical_ brief_pdf (accessed October 2009).

37 Stephens ML, Conlee K, Alvino G, et al: Possibilities for refinement and reduction: future improvements within regulatory testing. ILAR J 2002;43(suppl):S74-S79.

38 Greaves P, Williams A, Eve M: First dose of potential new medicines to humans: how animals can help. Nat Rev Drug Disc 2004;3:226236.

39 Olson H, Betton G, Robinson D, et al: Concordance of the toxicity of pharmaceuticals in humans and in animals. Regul Toxicol Pharmacol 2000;32:56-67.

40 Lo WY, Friedman JM: Teratogenicity of recently introduced medications in human pregnancy. Obstet Gynecol 2002;100:465473.

41 Ennever FK, Lave LB: Implications of the lack of accuracy of the lifetime rodent bioassay for predicting human carcinogenicity. Regul Toxicol Pharmacol 2003;38:52-57. 
42 Sung GT, Sun Y: Animal laboratory training: current status and how essential is it?; in Hemal AK, Menon M (eds): Robotics in Genitourinary Surgery. London, Springer, 2011, pp 147-156.

43 Hammoud MM, Nuthalapaty FS, Goepfert AR, et al: To the point: medical education review of the role of stimulators in surgical training. Am J Obstet Gynecol 2008; 199:338343.

44 Vlaovic PD, Sargent ER, Boker JR, et al: Immediate impact of an intensive one-week laparoscopy training program on laparoscopic skills among postgraduate urologists. JSLS 2008; $12: 1-8$.

-45 Pierorazio PM, Allaf ME: Minimally invasive surgical training: challenges and solutions. Urol Oncol 2009;27:208-213.

-46 Roberts KE, Bell RL, Duffy AJ: Evolution of surgical skills training. World J Gastroenterol 2006;12:3219-3224.

-47 Wignall GR, Denstedt JD, Preminger GM, et al: Surgical stimulation: a urological perspective. J Urol 2008;179:1690-1699.

48 Balasundaram I, Aggarwal R, Darzi A: Shortphase training on a virtual reality simulator improves technical performance in tele-robotic surgery. Int J Med Robot 2008;4:139145.

49 Lin DW, Romanelli JR, Kuhn JN, et al: Computer-based laparoscopic and robotic surgical stimulators: performance characteristics and perceptions of new users. Surg Endosc 2009; 23:209-214

50 Horrobin DF: Modern biomedical research an internally self-consistent universe with little contact with medical reality? Nat Rev Drug Disc 2003;2:151-154.
Fletcher RH: Evaluation of interventions. J Clin Epidemiol 2002;55:1183-1190.

52 Chalmers I: Well-informed uncertainties about the effects of treatments. BMJ 2004;328: 475-476.

53 Striker BH, Psaty BM: Education and debate article: detection, verification and quantification of adverse drug reactions. BMJ 2004;329: $44-47$.

54 Neumann A, Weill A, Ricordeau P, et al: Pioglitazone and risk of bladder cancer among diabetic patients in France: a populationbased cohort study. Diabetologia 2012;55: 1953-1962

55 Zhu Z, Shen Z, Lu Y, et al: Increased risk of bladder cancer with pioglitazone therapy in patients with diabetes: a meta-analysis. Diabetes Res Clin Pract 2012;98:159-163.

56 European Medicines Agency: European Medicines Agency recommends new contra-indications and warnings for pioglitazone to reduce small increased risk of bladder cancer. http://www.ema.europa.eu/docs/en_GB/ document_library/Press_release/2011/07/ WC500109176.pdf (accessed January 23, 2013).

57 Piccinni C, Motola D, Marchesini G, Poluzz $\mathrm{E}$ : Assessing the association of pioglitazone use and bladder cancer through drug adverse event reporting. Diabetes Care 2011;34:13691371.

58 Morris T, Goulet S, Morton D: The international symposium on regulatory testing and animal welfare: recommendations on best scientific practices for animal care in regulatory toxicology. ILAR J 2002;43(suppl):S123S125.

59 Morton DB, Jennings M, Buckwell A, et al Refining procedures for the administration of substances. Lab Anim 2001;35:1-41.
60 Nicholson A, Sandler J, Siedle T: An evaluation of the US high production volume (HPV) chemical-testing programme. A study in (ir) relevance, redundancy and retro thinking. Altern Lab Anim 2004;32(suppl 1):335-341.

61 Combes RD, Balls M: How much flexibility is possible when validating new in vivo toxicity test methods? Altern Lab Anim 2003;31:225232

62 Dunn DA, Kooyman DL, Pinkert CA: Foundation review: transgenic animals and their impact on the drug discovery industry. Drug Discov Today 2005; 10:757-767.

63 May M: A new era for clinical models. Science 2012;335:994-996.

64 Carlson H-E, Schapiro JS, Farah I, et al: Use of primates in research: a global overview. Am J Primatol 2004;65:225-237.

65 Shively CA, Clarkson TB: The unique value of primate models in translational research. Am J Primatol 2009;71:715-721.

- 66 C. elegans Sequencing Consortium: Genome sequence of the nematode $C$. elegans: a platform for investigating biology. Science 1998; 282:2012-2018.

67 McClellan-Green P, Romano J, Oberdorster E: Does gender really matter in contaminant exposure? A case study using invertebrate models. Environ Res 2007;104:183-191.

68 Van de Waterbeemd H, Gifford E: ADMET in silico modeling: towards prediction paradise? Nat Rev Drug Discov 2003;2:192-204.

69 Bikandi J, Millan RS, Rementeria A, Garaizar $\mathrm{J}$ : In silico analysis of complete bacterial genomes: PCR, AFLP-PCR and endonuclease restriction. Bioinformatics 2004;20:798-799.

-70 Kalendar R, Lee D, Schulman AH: Java web tools for PCR, in silico PCR, and oligonucleotide assembly and analysis. Genomics 2011; 98:137-144.
Current Status of Animal

Experimentation
Med Princ Pract 2013;22(suppl 1):52-61 